\title{
Autoconceito e ansiedade escolar: um estudo com alunos do ensino fundamental
}

\author{
Monalisa Muniz \\ Universidade Federal de São Carlos - São Carlos - SP - Brasil \\ Débora Cecílio Fernandes \\ Universidade Estadual do Centro-Oeste - Guarapuava - PR - Brasil Paraná
}

\begin{abstract}
Resumo
O objetivo do trabalho foi verificar o quanto o autoconceito está associado com ansiedade escolar. Para isso, 195 crianças de ambos os sexos, de sete a 11 anos, estudantes do $2^{\circ}$ ao $5^{\circ}$ ano do Ensino Fundamental de uma escola particular, participaram voluntariamente respondendo a Escala de Autoconceito Infanto-Juvenil e a Escala de Ansiedade Escolar. Os resultados apontaram várias correlações negativas entre as dimensões avaliadas pela escala de autoconceito com a ansiedade escolar. A dimensão social da escala de autoconceito foi a que apresentou maior correlação, de forma negativa, com a ansiedade. Esse dado se confirmou na análise de regressão que apontou a dimensão social como melhor preditora da ansiedade escolar. Apesar das correlações encontradas, duas dimensões do autoconceito, Familiar e Escolar, não apresentaram relação significativa com a escala de ansiedade escolar, exceto a Escolar para o $2^{\circ}$ ano, mas de forma positiva e baixa.
\end{abstract}

Palavras-chave: Autoconceito; psicologia escolar; aprendizagem.

\section{Self-concept and school anxiety: a study of elementary students}

\begin{abstract}
The aim of this article was to verify how the self is associated with school anxiety. For this, 195 children of both sexes, from seven to 11 years, students from 2nd to 5th year of elementary school to a private school, volunteered answering Self Concept Scale for Children and Youth and School Anxiety Scale. The results showed a number of negative correlations between the dimensions evaluated by the scale of self with school anxiety. The social dimension of self-concept scale showed the highest correlation negatively with anxiety. This finding was confirmed in the regression analysis which showed the social dimension as the best predictor of school anxiety. Despite the correlations found, two dimensions of self, Family and School, showed no significant relationship with school anxiety scale, except the School for the 2nd year, but in a positive and low form.
\end{abstract}

Keywords: Self concept; school psychology; learning.

\section{Auto concepto y ansiedad escolar: un estudio con alumnos de la enseñanza primaria}

\section{Resumen}

El objetivo del estudio fue verificar en qué medida el auto concepto está asociado con la ansiedad escolar. Para eso, 195 niños de ambos sexos, de siete a 11 años, estudiantes del $2^{\circ}$ al $5^{\circ}$ curso de la Enseñanza Primaria de una escuela particular, participaron voluntariamente respondiendo la Escala de Auto concepto Infanto-Juvenil y la Escala de Ansiedad Escolar. Los resultados apuntaron varias correlaciones negativas entre las dimensiones evaluadas por la escala de auto concepto con la ansiedad escolar. La dimensión social de la escala de auto concepto fue la que presentó más correlación, de forma negativa, con la ansiedad. Ese dato se confirmó en el análisis de regresión que apuntó la dimensión social como mejor predicción de la ansiedad escolar. A pesar de las correlaciones encontradas, dos dimensiones del auto concepto, Familiar y Escolar, no presentaron relación significativa con la escala de ansiedad escolar, excepto la Escolar para el $2^{\circ}$ curso, pero de forma positiva y baja.

Palabras clave: Autoimagen; psicología escolar; aprendizaje. 


\section{Introdução}

A aprendizagem no ambiente escolar é propiciada por diversos fatores, dentre esses o cognitivo, o social e o emocional. O aprender vai além da capacidade intelectual da pessoa, pois depende também da forma como ela se relaciona com os seus pares, com o professor e como sente e percebe esse ambiente escolar. Essa afirmação pode ser sustentada por meio de diversos estudos sobre os fatores associados ao desempenho acadêmico (Berger, Alcalay, Torreti, \& Milicic, 2011; Oliveira \& Soares, 2011; Cia, Barham, \& Fontaine, 2012; Tinajero, Lemos, Araújo, Ferraces, \& Páramo, 2012).

Especialmente quanto aos aspectos emocionais, diversas pesquisas já foram realizadas procurando mostrar a relação desse fator com o desempenho acadêmico. Conforme pontuado por Costa e Boruchovitch (2004), já há um reconhecimento da interferência das variáveis afetivas no rendimento escolar, sendo imprescindíveis as pesquisas de âmbito nacional que buscam compreender essa relação.

O estudo sobre o quanto e como as variáveis afetivas e emocionais contribuem para o processo de ensino-aprendizagem deve ter a finalidade de servir como base para programas de intervenção que promovam mudanças e melhorias da afetividade e das emoções. No entanto, para que esses programas possam ser desenvolvidos é importante que se investigue detalhadamente as variáveis afetivas e emocionais no ambiente escolar, não somente a associação com o desempenho, mas a relação entre elas.

O presente trabalho abordará dois construtos, um afetivo representado pelo autoconceito e outro emocional, abordando ansiedade escolar. Assim, considera-se que o afeto é uma qualidade emocional de uma representação mental e a emoção é uma reação afetiva intensa, de curta duração e propiciada por estímulos internos ou externos (Dalgalarrondo, 2000). O autoconceito conforme definido por Shavelson, Hubner, e Stanton (1976 citado por Sisto \& Martinelli, 2004) é a percepção que o indivíduo tem de si resultante das experiências vividas com os outros e o valor que atribui a sua própria conduta.

Carneiro, Martinelli e Sisto (2003) acrescentam que a construção do autoconceito é lenta e se desenvolve por meio das experiências vividas e interação com outros indivíduos. Crianças que passam por experiências desagradáveis, que são tratadas de maneira grosseira, rude e negligente, principalmente por adultos significativos, como pais e professores, tendem a desenvolver um autoconceito menos valorizado sobre si mesmas. As crianças tendem a incorporar as ideias que os adultos significativos têm sobre elas, mesmo que não sejam condizentes com o que a criança realmente é. Os mesmos autores mencionam a multidimensionalidade do autoconceito e que para eles podem ser englobadas quatro dimensões, além da geral, que são o autoconceito social, escolar, familiar e pessoal. Dessa forma, um indivíduo pode apresentar autoconceito baixo em questões escolares, mas alto em sociais.

Nas medidas utilizadas para avaliar o autoconceito, como a Escala Piers Harris de Autoconceito, a Escala Self-Description Questionnaire e a Escala de Autoconceito
Infanto-Juvenil, há uma dimensão relacionada ao ambiente escolar, o que parece indicar a importância do autoconceito nesse contexto. Do mesmo modo, a manifestação de sintomas de ansiedade na escola também se relaciona com as dificuldades de aprendizagem, motivação, desempenho acadêmico, entre outros. Com isso, instiga-se a pergunta sobre qual a relação entre essas duas variáveis, autoconceito e ansiedade escolar e que o presente trabalho tem a finalidade de investigar.

A ansiedade, segundo Dalgalarrondo (2000), pode ser compreendida como um incômodo desagradável interno, que interfere no humor, deixando a pessoa com uma sensação desconfortável, uma inquietação interna junto às percepções negativas sobre o futuro e manifestando sintomas somáticos e fisiológicos, como sudorese, tensão muscular, tonturas, entre outros, e sintomas psíquicos, por exemplo, apreensão e desconforto mental. Além disso, a ansiedade é considerada um estado psicológico e fisiológico, caracterizada por aspectos cognitivo, somático, emocional e comportamental (Seligman, Walker, \& Rosenhan, 2001; Craske \& cols., 2009). Trata-se de uma condição orientada para o futuro, acompanhada de uma apreensão relacionada com a percepção de falta de controle e previsão de eventos potencialmente aversivos (Barlow, 2002). Conforme pontuado por Oliveira e Sisto (2002), essas manifestações da ansiedade podem estar relacionadas a eventos passageiros ligados a algo específico ou ser uma forma permanente do indivíduo lidar com as situações do dia-a-dia, como parte da sua própria constituição da personalidade.

A escola é um contexto que pode gerar situações que causam ansiedade no aluno, como as regras a serem cumpridas e as avaliações (Asbahr, 2004; Mychailyszyn, Mendez, \& Kendall, 2010). Há estudos que sugerem que a ansiedade deve sempre ser considerada no ambiente escolar para compreender melhor os comportamentos e o rendimento do aluno, como por exemplo, as pesquisas de Furlam, Rosas, Heredia, Piemontesi, e Illbele (2009), Fonseca, Cardoso, Muszkat, e Bueno (2011), Pereira, Barros, e Mendonça (2011), e Fernandes e Silveira (2012).

Apesar das pesquisas já realizadas sobre a ansiedade e o ambiente escolar, os instrumentos utilizados para avaliar a ansiedade não são específicos das situações escolares e tendem a diferir no conteúdo, sendo uns mais delimitados a sintomas físicos, outros mais aos psicológicos (Oliveira \& Sisto, 2002). A ansiedade, em geral, está relacionada ao bom desenvolvimento na vida escolar, mas assim como ocorre com o construto do autoconceito, é interessante que também se investigue a ansiedade nesse particular, ainda mais considerando que a ansiedade pode derivar de algo contingencial. Nesse sentido em 2002, Oliveira e Sisto desenvolveram a Escala de Ansiedade Escolar, que será utilizada no presente estudo.

Como visto, as pesquisas sobre autoconceito e ansiedade apoiam a necessidade de se compreender esses construtos no ambiente escolar, bem como analisar como esses fatores interferem no processo de ensino-aprendizagem. Além de ser constatada, de forma separada, a relevân- 
cia de ambos os construtos, também é importante investigar a relação entre eles. As pesquisas que investigam a relação entre esses dois construtos são escassas, principalmente quando se considera a ansiedade escolar, o que indica a necessidade de que mais estudos sejam realizados.

Nesse contexto, foram encontradas três pesquisas que relatam a associação entre o autoconceito e a ansiedade. A primeira aborda o autoconceito em matemática e ansiedade geral e para a estatística. O efeito do autoconceito em matemática, auto-eficácia percebida, atributos de sucesso e fracasso, foi explorado com testes de ansiedade geral e ansiedade específica para estatística no estudo de Bandalos, Yates, e Thorndike-Christ (1995). Participaram da pesquisada 338 estudantes universitários. O estudo obteve correlações significativas negativas baixas entre o autoconceito em matemática e o teste de ansiedade geral e específico de estatística.

$\mathrm{Na}$ segunda pesquisa, não foi investigada diretamente a ansiedade, mas sim o traço de Neuroticismo, que por sua vez descreve pessoas ansiosas, depressivas, com baixa-estima e oscilações de humor (Fernandes, Bartholomeu, Rueda, Suehiro, \& Sisto, 2005). O objetivo do trabalho foi verificar a relação entre autoconceito e personalidade em 389 crianças com idades entre oito e 10 anos. Os instrumentos aplicados foram a Escala de Autoconceito Infanto-Juvenil que avalia as dimensões pessoal, social, escolar e familiar, e a Escala de Traços de Personalidade para Crianças que mensura Extroversão, Psicoticismo, Socialização e Neuroticismo. Dentre as diversas correlações encontradas, observaram-se, para os meninos, correlações positivas e baixas entre Neuroticismo com Autoconceito Pessoal e Social. Já no grupo das meninas, foram pontuadas correlações negativas e baixas entre Neuroticismo e Autoconceito Familiar e correlação positiva e baixa com Autoconceito Pessoal.

Já no terceiro estudo, Matos e Lobo (2009) buscaram averiguar o autoconceito, o coping e a saúde mental de adolescentes com Paralisia Cerebral. Um dos objetivos foi investigar a relação do autoconceito com depressão, ansiedade e sintomatologia psicopatológica. A ansiedade foi avaliada por meio do Revised Children's Manifest Anxiety Scale e o autoconceito com a Piers-Harris Self-Concept Questionnaire. A amostra foi composta por 78 indivíduos com Paralisia Cerebral e com idades variando de 12 a 19 anos. Os resultados indicaram associações significativas negativas baixas e moderadas entre os fatores do autoconceito (comportamental, ansiedade, estatuto intelectual/escolar, popularidade, aparência/atributos físicos e satisfação/ felicidade) com a escala de ansiedade.

As correlações negativas entre autoconceito e ansiedade podem ser parcialmente explicadas pela compreensão de Carneiro, Martinelli e Sisto (2003) e González, Cabanach, e Valle Arias (1998) acerca do autoconceito. Esses autores argumentam que o autoconceito tende a ser organizador e integrador das experiências vivenciadas pelos indivíduos, regula os estados afetivos, motiva e orienta o comportamento. Assim, é possível supor que indivíduos com autoconceito mais positivo são capazes de administrar melhor seus sen- timentos e sua maneira de se comportar diante de diversas situações, o que produziria uma redução dos sintomas de ansiedade. As pesquisas de Bandalos e cols. (1995) e Matos e Lobo (2009) concordam com esse posicionamento e o estudo de Fernandes e cols. (2005) apoia parcialmente essa ideia mediante a correlação negativa e baixa entre Neuroticismo e autoconceito familiar em meninas.

No entanto, essa relação ainda não está clara, pois Fernandes e cols. (2005) revelaram correlações positivas entre autoconceito e neuroticismo, o que pode representar certo grau de ansiedade. Nesse sentido, o presente trabaIho tem o objetivo de pesquisar as possíveis relações entre autoconceito e ansiedade no contexto escolar. Mais especificamente, o presente trabalho buscou verificar as relações entre as dimensões pessoal, familiar, social e escolar do autoconceito com a ansiedade escolar. Dessa forma, procurar-se-á ter melhor compreensão de ambos os construtos, o que contribuirá para o desenvolvimento de possíveis intervenções que melhorem a aprendizagem dos alunos. Como pontuado por Oliveira e Sisto (2002), o aluno pode vivenciar situações ansiógenas na escola diante diversas situações novas e inesperadas que tendem a ocorrer e que não conseguem resolver. Então, se o autoconceito positivo for uma das variáveis que ajudam na diminuição dessa ansiedade, deverá ser mais um aspecto a ser trabalhado nas intervenções.

\section{Método}

\section{Participantes}

A amostra foi composta por 195 estudantes, $101(51,8 \%)$ meninas e $94(48,2 \%)$ meninos do $2^{\circ}$ ao $5^{\circ}$ ano do Ensino Fundamental de uma escola particular do estado de Minas Gerais. Separando por ano, o percentual de participantes é $21 \%$ do $2^{\circ}$ ano com média de idade 7,41 ( $D P=0,49), 29,2 \%$ do $3^{\circ}$ e média de idade $8,3(\mathrm{DP}=0,46)$, $28,2 \%$ do $4^{\circ}$ idade média de $9,24(\mathrm{DP}=0,46)$ e $21,5 \%$ do $5^{\circ}$ ano com a idade média de 10,33 ( $\mathrm{DP}=0,47)$.

\section{Instrumentos}

Para a coleta dos dados dois instrumentos foram utilizados na pesquisa. A Escala de Autoconceito Infanto-Juvenil e o Inventário de Ansiedade Escolar.

Escala de Autoconceito Infanto-Juvenil-EAC-IJ (Sisto \& Martinelli, 2004)

A Escala de Autoconceito Infanto-Juvenil-EAC-IJ avalia o autoconceito em crianças e adolescentes de oito a 16 anos de idade. A escala avalia quatro dimensões do autoconceito, que são pessoal, social, escolar e familiar, além da dimensão geral que é a soma das anteriores. Autoconceito pessoal descreve a pessoa que se percebe de bem com a vida, lida com seus problemas sem dificuldades ou ansiedade extrema quando se depara com situações consideradas preo- 
cupantes. O Autoconceito social se refere às relações sociais com os colegas e como o sujeito se percebe nessas relações. Diz respeito à avaliação de suas capacidades intelectuais, o querer ser igual ou melhor que os outros e a disposição em ajudar e receber ajuda quando necessário. Já o Autoconceito escolar se baseia nas relações interpessoais dentro do ambiente escolar e é como o indivíduo percebe a sua capacidade para liderar, para ser reconhecido academicamente pela sua expertise, julgar que suas ideias são aceitas por seus colegas e que estes o vejam como bondoso e divertido. Por fim, o Autoconceito familiar trata do comportamento adotado nas situações do dia-a-dia em casa com os pais e irmãos. É a percepção dos sentimentos em relação aos irmãos, o cuidado com as coisas de casa e os comportamentos verdadeiros e corretos conforme solicitados pela família.

A escala é composta por 20 itens, dos quais seis se referem ao autoconceito social, quatro ao autoconceito familiar, cinco ao autoconceito escolar e cinco ao autoconceito pessoal. As alternativas de respostas são três (sempre, às vezes e nunca) e o sujeito deve assinalar a opção que melhor o descreve. A aplicação da escala pode ser coletiva ou individual e não há limite de tempo, mas os sujeitos geralmente terminam entre 5 a 10 minutos. Para a correção, pontuam-se as alternativas com 0, 1 e 2, faz-se a somatória de cada dimensão e da global, transforma-se o resultado bruto em percentil com o auxílio de uma tabela de normatização e quanto maior o percentil (o resultado), maior o autoconceito. Estudos psicométricos apontam validade e precisão do instrumento.

Inventário de Ansiedade Escolar (Oliveira \& Sisto, 2002)

O inventário tem o objetivo de avaliar a ansiedade no contexto escolar e os itens construídos se baseiam nas diretrizes e definições dos transtornos de ansiedade contemplados no Manual de Diagnóstico e Estatística da Associação Norte-Americana de Psiquiatria (DSM-IV) e a Classificação Internacional de Diagnósticos (CID-10). O instrumento é composto por 38 itens e três opções de respostas (sempre, às vezes, nunca). Há oito itens de compensação que representam situações mais agradáveis da vida escolar para compensar os demais itens com significado negativo, então estes não entram na somatória.

As pontuações variam de 0 a 60 e, até o momento, o escore é geral, sem distinguir dimensões na escala. Quanto maior a pontuação, maior o nível de ansiedade escolar. Para a interpretação do inventário, considera-se que pontuações acima de 12 são preocupantes, pois conforme o DSM-IV, a presença de seis situações ansiógenas é suficiente para causar prejuízo significativo na vida da pessoa (Oliveira, 2001). A escala pode ser aplicada de forma individual ou coletiva e há estudos psicométricos comprovando validade e precisão para crianças de sete a 12 anos de idade (Oliveira, 2012).

\section{Procedimento}

Os dados coletados se referem a dois estudos independentes, mas que utilizaram a mesma amostra e período de aplicação dos instrumentos. Com isso, inicialmente os projetos foram submetidos ao Comitê de Ética e os números dos protocolos aprovados são: $1737 / 11$ para a coleta com a escala de ansiedade escolar e 1738/11 para a coleta com o instrumento de autoconceito.

Após aprovação, combinou-se com a direção da escola uma data para a aplicação e nesse mesmo dia foi entregue os Termos de Consentimento Livre e Esclarecido-TCLE para que as crianças levassem para os responsáveis assinarem. No dia da aplicação, somente participou da pesquisa os alunos com o TCLE preenchido e assinado corretamente pelos responsáveis.

A coleta foi realizada pelas próprias pesquisadoras e alunos de iniciação científica treinados para auxiliarem nesse momento. Os instrumentos foram aplicados de forma coletiva e os itens foram lidos, um a um, pelas pesquisadoras que aguardavam os sujeitos responderem para passar ao próximo item. A duração para a realização dos dois testes foi em média 30 minutos.

\section{Resultados}

Inicialmente serão apresentados os resultados referentes à estatística descritiva dos dados de cada instrumento obtidos pela amostra. A Tabela 1 mostra a média, desvio padrão, pontuação mínima e máxima da Escala de Autoconceito Infanto-Juvenil por idade e gênero, seguindo a mesma separação contida nas tabelas normativas do manual, assim também pode-se fazer uma comparação com a amostra de normatização.

Comparando com os dados da amostra de normatização, contidos no manual da Escala de Autoconceito, verificaram-se para o sexo feminino valores na média ou acima da média nas dimensões do autoconceito, exceto para o Escolar que foi abaixo da média para todas as idades, assim como familiar e geral para a idade de nove anos. Com relação ao sexo masculino, as pontuações foram mais baixas, o Escolar ficou abaixo da média para todas as idades, o Social próximo da média e na média para 11 anos, enquanto que o Familiar ficou abaixo da média, com exceção das crianças de 11 anos que obtiveram pontuação próxima da média. No escore geral, as idades de nove e 10 anos ficaram abaixo da média. Esses resultados indicam que os meninos apresentaram autoconceito mais negativo ao comparar com a amostra normativa. No caso das meninas, essa tendência foi observada apenas para o autoconceito Escolar e para a idade de nove anos no Familiar e Geral. Ressalta-se que para a idade de sete anos não há normas no manual, mas optou-se por compará-las com a idade de oito anos, então os resultados para essa idade devem ser interpretados com cautela.

Para a escala de ansiedade foram realizadas as estatísticas descritivas, também por idade e sexo. Na Tabela 2, visualizam-se as estatísticas do Inventário de Ansiedade Escolar da presente amostra.

Ao considerar o critério de 12 pontos no inventário como um indicador preocupante do nível de ansiedade das 
Tabela 1. Estatística descritiva de média e desvio padrão da amostra, por idade e sexo, no instrumento de autoconceito.

\begin{tabular}{|c|c|c|c|c|c|}
\hline Idade & Pessoal & Escolar & Familiar & Social & Geral \\
\hline \multicolumn{6}{|c|}{ Feminino } \\
\hline 7 & $5,93(2,37)$ & $2,60(1,35)$ & $6,60(1,50)$ & $10,53(2,38)$ & $25,65(5,08)$ \\
\hline 8 & $6,45(1,61)$ & $4,24(2,13)$ & $6,62(1,26)$ & $10,24(2,47)$ & $27,55(4,45)$ \\
\hline 9 & $5,56(2,30)$ & $3,78(2,20)$ & $5,33(1,24)$ & $9,04(3,07)$ & $23,81(5,51)$ \\
\hline 10 & $5,05(1,77)$ & $3,52(1,69)$ & $6,29(1,31)$ & $10,14(1,90)$ & $25(2,85)$ \\
\hline 11 & $4,89(1,90)$ & $3,44(1,81)$ & $6,33(1,00)$ & $10,56(2,00)$ & $25,22(4,97)$ \\
\hline \multicolumn{6}{|c|}{ Masculino } \\
\hline 7 & $6,67(1,94)$ & $4,33(3,20)$ & $5,11(2,03)$ & $8,89(1,97)$ & $25(4,90)$ \\
\hline 8 & $6,97(2,08)$ & $4,62(2,26)$ & $5,14(1,71)$ & $9,60(3,13)$ & $26,31(5,48)$ \\
\hline 9 & $6,45(2,25)$ & $3,56(2,17)$ & $5,10(1,47)$ & $9,70(2,45)$ & $24,72(4,94)$ \\
\hline 10 & $5,43(2,04)$ & $3,52(1,78)$ & $5,29(1,62)$ & $9,52(2,80)$ & $23,76(5,11)$ \\
\hline 11 & $6,40(1,82)$ & $3,20(1,79)$ & $5,80(1,64)$ & $10,20(1,92)$ & $25,60(2,61)$ \\
\hline
\end{tabular}

Tabela 2. Estatística descritiva de média e desvio padrão da amostra, por idade e sexo, no instrumento de ansiedade escolar.

\begin{tabular}{ccc}
\hline Idade & Feminino/M e DP & Masculino/ M e DP \\
\hline 7 & $23,33(10,61)$ & $28(12,01)$ \\
8 & $21,69(7,95)$ & $24,03(9,38)$ \\
9 & $22,93(8,54)$ & $22,67(9,55)$ \\
10 & $21,14(9,82)$ & $22,76(9,30)$ \\
11 & $18,67(7,89)$ & $15,20(6,94)$ \\
\hline
\end{tabular}

crianças, os dados mostrados na Tabela 2 apontam que a média para todas as idades está acima dos 12 pontos. As meninas e os meninos de sete anos são os que apresentam ansiedade mais alta, de acordo com o instrumento aplicado.

As estatísticas descritivas são importantes para compreender o comportamento da amostra frente os testes aplicados e, consequentemente, colaborar para que as análises inferenciais sejam mais bem elucidadas. No entanto, o objetivo principal do trabalho é verificar a relação entre autoconceito e ansiedade escolar e, para isso, as próximas análises serão inferenciais e de associação entre os dados. $\mathrm{Na}$ Tabela 3 encontram-se as correlações obtidas entre as pontuações dos testes, tanto no geral, quanto por ano escolar e sexo. Nessas análises, ao invés da idade, optou-se pelos anos escolares para que as informações obtidas sejam mais próximas do contexto escolar.

Por meio da Tabela 3 identificam-se várias correlações significativas entre o autoconceito e suas dimensões com a ansiedade escolar. No autoconceito pessoal foram constatadas correlações significativas negativas, baixas e moderadas, com a ansiedade escolar em todos os anos escolares. O mesmo padrão de correlações foi observado para o autoconceito social e geral, exceto no $2^{\circ}$ ano, e as magnitudes das correlações moderadas foram maiores, de modo que três delas no autoconceito social estão próximas de serem consideradas altas. No caso do autoconceito escolar observa-se uma correlação significativa com a ansiedade escolar no $3^{\circ}$ ano e com magnitude baixa e positiva. Por fim, autoconceito familiar e ansiedade escolar não apresentaram correlações significativas. A interpretação das magnitudes segue o sugerido por Dancey e Reidy (2006) que consideram até 0,40 baixa, acima de 0,40 até 0,70 moderada e acima de 0,70 alta.

Procurando investigar melhor as relações encontradas, fez-se uma análise de regressão utilizando o método stepwise e considerando como variável dependente a ansiedade e independente as dimensões do autoconceito. Esse procedimento permite visualizar qual dimensão do 
Tabela 3. Correlações entre a escala de autoconceito e a escala de ansiedade escolar por amostra geral, série e sexo.

\begin{tabular}{|c|c|c|c|c|c|}
\hline & Pessoal & Escolar & Familiar & Social & Geral \\
\hline \multicolumn{6}{|c|}{ Geral } \\
\hline Ansiedade & $-0,42^{* *}$ & 0,12 & $-0,08$ & $-0,53^{* *}$ & $-0,43^{* *}$ \\
\hline \multicolumn{6}{|c|}{$2^{\circ} \mathrm{Ano}$} \\
\hline Ansiedade & $-0,33^{*}$ & $-0,08$ & 0,05 & $-0,16$ & $-0,27$ \\
\hline \multicolumn{6}{|c|}{$3^{\circ} \mathrm{Ano}$} \\
\hline Ansiedade & $-0,49^{* *}$ & $0,33^{*}$ & $-0,09$ & $-0,67^{* *}$ & $-0,45^{* *}$ \\
\hline \multicolumn{6}{|c|}{$4^{\circ} \mathrm{Ano}$} \\
\hline Ansiedade & $-0,52^{* *}$ & 0,11 & $-0,16$ & $-0,67^{* *}$ & $-0,55^{* *}$ \\
\hline \multicolumn{6}{|c|}{$5^{\circ} \mathrm{Ano}$} \\
\hline Ansiedade & $-0,55^{* *}$ & 0,07 & $-0,14$ & $-0,66^{* *}$ & $-0,63^{* *}$ \\
\hline \multicolumn{6}{|c|}{ Feminino } \\
\hline Ansiedade & $-0,46^{* *}$ & 0,15 & $-0,18$ & $-0,56^{* *}$ & $-0,49^{* *}$ \\
\hline \multicolumn{6}{|c|}{ Masculino } \\
\hline Ansiedade & $-0,41^{* *}$ & 0,09 & 0,05 & $-0,49^{* *}$ & $-0,37^{* *}$ \\
\hline
\end{tabular}

${ }^{*} p<0,05{ }^{* *} p<0,01$

Tabela 4. Regressão linear por stepwise entre a variável dependente ansiedade escolar e as variáveis independentes do autoconceito.

\begin{tabular}{|c|c|c|c|c|c|c|c|c|}
\hline Modelo & $\begin{array}{l}\text { V a r i á v e i s } \\
\text { preditoras }\end{array}$ & B & $\begin{array}{llll} & r & r & 0 \\
\text { Padrão } & \\
\end{array}$ & $b$ & $t$ & $p$ & $F$ & $\mathbf{R}^{2}$ \\
\hline \multicolumn{9}{|l|}{ Geral } \\
\hline \multirow[t]{4}{*}{3} & (Constant) & 41,689 & 2,854 & & 14,606 & 0,00 & 34,74 & 0,34 \\
\hline & ACST & $-1,998$ & 0,317 & $-0,56$ & $-6,305$ & 0,00 & & \\
\hline & ACPT & $-1,624$ & 0,343 & $-0,37$ & $-4,730$ & 0,00 & & \\
\hline & ACTT & 0,405 & 0,205 & 0,21 & 1,976 & 0,05 & & \\
\hline \multicolumn{9}{|l|}{$2^{a}$ Ano } \\
\hline \multirow[t]{2}{*}{1} & (Constant) & 34,713 & 5,218 & & 6,653 & 0,00 & 0,48 & 0,08 \\
\hline & ACPT & $-1,755$ & 0,795 & $-0,33$ & $-2,209$ & 0,03 & & \\
\hline \multicolumn{9}{|l|}{$3^{a}$ Ano } \\
\hline \multirow[t]{4}{*}{3} & (Constant) & 42,186 & 3,759 & & 11,222 & 0,00 & 22,71 & 0,54 \\
\hline & ACST & $-1,747$ & 0,327 & $-0,55$ & $-5,336$ & 0,00 & & \\
\hline & ACET & 1,089 & 0,354 & 0,28 & 3,072 & 0,00 & & \\
\hline & ACPT & $-0,924$ & 0,440 & $-0,22$ & $-2,099$ & 0,04 & & \\
\hline \multicolumn{9}{|l|}{$4^{a}$ Ano } \\
\hline \multirow[t]{4}{*}{3} & (Constant) & 41,057 & 3,816 & & 10,758 & 0,00 & 20,87 & 0,53 \\
\hline & ACST & $-2,485$ & 0,506 & $-0,81$ & $-4,910$ & 0,00 & & \\
\hline & ACPT & $-2,175$ & 0,595 & $-0,51$ & $-3,657$ & 0,00 & & \\
\hline & ACTT & 0,714 & 0,344 & 0,44 & 2,073 & 0,04 & & \\
\hline \multicolumn{9}{|l|}{$5^{a}$ Ano } \\
\hline \multirow[t]{3}{*}{2} & (Constant) & 57,983 & 5,184 & & 11,185 & 0,00 & 29,16 & 0,58 \\
\hline & ACST & $-2,675$ & 0,500 & $-0,56$ & $-5,344$ & 0,00 & & \\
\hline & ACPT & $-1,941$ & 0,480 & $-0,42$ & $-4,044$ & 0,00 & & \\
\hline \multicolumn{9}{|l|}{ Feminino } \\
\hline \multirow[t]{3}{*}{2} & (Constant) & 44,370 & 3,006 & & 14,761 & 0,00 & 29,94 & 0,37 \\
\hline & ACST & $-1,571$ & 0,309 & $-0,45$ & $-5,087$ & 0,00 & & \\
\hline & ACPT & $-1,190$ & 0,383 & $-0,27$ & $-3,110$ & 0,00 & & \\
\hline \multicolumn{9}{|c|}{ Masculino } \\
\hline & (Constant) & 45,941 & 3,612 & & 12,718 & 0,00 & 20,66 & 0,30 \\
\hline & ACST & $-1,445$ & 0,328 & $-0,40$ & $-4,401$ & 0,00 & & \\
\hline & ACPT & $-1,374$ & 0,410 & $-0,30$ & $-3,350$ & 0,00 & & \\
\hline
\end{tabular}


autoconceito prediz melhor a ansiedade escolar. Na Tabela 4 encontram-se as os resultados extraídos dessa análise por amostra geral, ano escolar e sexo.

A Tabela 4 apenas mostra as variáveis que contribuíram para a predição da ansiedade escolar. Nota-se que o Autoconceito Social (ACST) e Pessoal (ACPT) são as dimensões preditoras em todos os anos escolares e sexo, exceto para $\circ 2^{\circ}$ ano escolar, cuja variável preditora foi apenas o Autoconceito Pessoal e, mesmo assim, de forma pouco preditiva, explicando $0,8 \%\left(R^{2}=0,08\right)$ da ansiedade escolar. Entre as dimensões, o Autoconceito Social se destaca como a primeira variável preditora, indicando ser a dimensão que melhor prediz a ansiedade escolar ao comparar com as demais variáveis.

As diferenças observadas na composição das variáveis preditoras são referentes à amostra geral, ao $3^{\circ}$ e $4^{\circ}$ ano escolar, além do $2^{\circ}$ ano que já foi mencionado. Para a amostra geral e o $4^{\circ}$ ano, o Autoconceito Geral (ACTT) é a dimensão preditora. Já no $3^{\circ}$ ano, a variável Autoconceito Escolar (ACET) também contribuiu para a predição da ansiedade escolar.

\section{Discussão}

A análise das estatísticas descritivas destacou o rebaixamento do Autoconceito Escolar em todos os anos escolares e em meninos e meninas. Esse dado indica que a amostra pesquisada tende a se perceber como menos hábil para os estudos escolares, menos capaz de liderar grupos, além de acreditar que suas ideias não são aceitas pelos colegas e que não são pessoas boas e divertidas na escola (Sisto \& Martinelli, 2004).

Na pesquisa de Schiavoni e Martinelli (2012), que investigaram o autoconceito de crianças aceitas e rejeitadas entre seus pares na escola, obteve-se a média de 4,9, e que pode ser considerada uma pontuação baixa do Autoconceito Escolar para o grupo de crianças isoladas (crianças que não foram citadas por outras crianças para brincar e estudar). No manual do teste utilizado pelas autoras, a média para sujeitos de oito a 11 anos é de seis pontos para os meninos e cinco para as meninas. Neste estudo, foram avaliadas as crianças com idades de sete a 11 anos.

O estudo de Schiavoni e Martinelli (2012), apesar de não ter comparado as médias da amostra com as de normatização do manual, ressalta, ao lado da presente pesquisa, a necessidade de investigar-se melhor a relação entre o autoconceito escolar, os anos escolares e o sexo dos participantes. Nesse sentido, é muito chamativa a semelhança das pontuações de autoconceito das crianças desta pesquisa e das crianças isoladas socialmente.

Outro dado interessante diz respeito às pontuações inferiores à média do manual nas dimensões do Autoconceito Social, Familiar e Geral para o sexo masculino. No caso das meninas, somente a idade de nove anos se mostrou abaixo da média em Autoconceito Familiar e Geral. As pontuações na dimensão geral da escala de autoconceito emergem das demais dimensões, então é importante que se compreenda o comportamento do sujeito em cada dimensão. A informação sobre as pontuações dos meninos é mais preocupante, pois o Autoconceito Escolar, Social e Familiar não se apresenta bem desenvolvido positivamente. Dessa forma, entende-se que os meninos da amostra não apresentam uma percepção positiva sobre si mesmos na escola, tendem a se avaliar como esquisitos, bobos, com pouca inteligência e habilidade para ajudar os amigos e apresentam comportamentos de isolamento frente ao fracasso. A tristeza, o descontentamento com os irmãos, descaso com as tarefas da casa e os comportamentos de mentir aos pais e inadequações na relação familiar, são refletidos na pontuação do Autoconceito Familiar da amostra de meninos da presente pesquisa (Sisto \& Martinelli, 2004). Como o autoconceito tem relação empiricamente comprovada com diversos construtos, entre eles o rendimento escolar, esses dados reforçam a necessidade de compreender meIhor o que está interferindo na formação do autoconceito, bem como o desenvolvimento de intervenções para esse aspecto afetivo.

Em relação à ansiedade manifesta no contexto escolar, Oliveira (2001) propôs que pontuações acima de 12 deveriam ser consideradas preocupantes, pois podem representar a manifestação da ansiedade em seis situações diferentes ou a manifestação de sintomas relativamente frequentes em 12 ocasiões ou ainda a combinação de sintomas relativamente frequentes e outros que ocorrem sempre. Assim, ao considerar esse critério, todos os grupos etários apresentaram níveis preocupantes de ansiedade, independente do sexo. As crianças de sete anos são as mais ansiosas, principalmente os meninos. Como a ansiedade pode estar relacionada com a exposição às novas situações escolares (Oliveira \& Sisto, 2002), os anos iniciais de escolarização podem ser condições propicias para aumentar a ansiedade no contexto escolar (Mychailyszyn \& cols., 2010). Nesse sentido, a criança se depara com situações novas como a sala de aula, com a necessidade de ser avaliada, de fazer novos companheiros, ser aceita socialmente, buscar estratégias de aprendizagem, entre outras. São situações novas para as quais a criança deve se adaptar e aprender como se comportar. Se a ansiedade é considerada como uma apreensão ou uma preocupação em relação ao futuro (Barlow, 2002; Craske \& cols., 2009), entende-se que o primeiro ano escolar seja o mais propenso a produzir esse tipo de reação nas crianças. No entanto, é necessário ponderar que o instrumento de ansiedade escolar é um screening e não um diagnóstico fim da ansiedade.

No que diz respeito à relação entre autoconceito e ansiedade escolar, observou-se que existe uma relação significativa entre esses dois construtos, confirmada tanto pelas correlações como pela análise de regressão. A maioria das correlações, exceto uma, foi moderada e algumas foram próximas da magnitude alta. Os resultados indicaram que o autoconceito geral correlaciona negativa e moderadamente com a ansiedade em todos os anos escolares, exceto o $2^{\circ}$ ano, que não foi constatada correlação significativa. Assim, 
entende-se a contribuição do construto autoconceito para a ansiedade escolar, sugerindo que as crianças que não têm boa percepção de si mesmas apresentam níveis mais altos de ansiedade escolar. É possível que a percepção negativa de si mesmo favoreça sentimentos de medo e sensações de apreensão em relação ao futuro como antecipação de encontros sociais na escola, das avaliações, das relações interpessoais etc.

Ao verificar cada dimensão do autoconceito, constata-se que entre o Autoconceito Pessoal e a Ansiedade Escolar houve correlações negativas e moderadas, exceto no $2^{\circ}$ ano que foi baixa. Esse resultado sugere que a criança com autoconceito pessoal adequado, que se sente bem consigo mesma, com menos preocupações e medos, tende a apresentar menos ansiedade escolar. Nesse sentido, Sisto e Martinelli (2004) descrevem o autoconceito pessoal como a forma pela qual a pessoa tende a agir diante das situações, se demonstra medos ou preocupações com os erros. Como uma das características da ansiedade é a apreensão e desconforto mental diante algumas situações (Dalgalarrondo, 2000), a pessoa com autoconceito pessoal adequado deveria apresentar menos ansiedade. Então os dados encontrados são coerentes e apontam a importância de ter o autoconceito pessoal bem desenvolvido para lidar melhor com a ansiedade escolar.

Igualmente, esta pesquisa corrobora os dados observados por Matos e Lobo (2009) que encontraram correlações negativas entre todas as dimensões de autoconceito, incluindo a pessoal, com uma escala de ansiedade. Os resultados da presente pesquisa também contribuem para sustentar os achados de Bandalos e cols. (1995) que apesar de não se referirem especificamente à matemática, também revelam que quanto maior o autoconceito (em matemática), menor o nível de ansiedade.

No entanto, a relação entre ansiedade e autoconceito pessoal encontrada na presente pesquisa não condiz com as correlações encontradas no trabalho de Fernandes e cols. (2005), que indicaram correlação positiva e baixa entre o traço Neuroticismo e Autoconceito Pessoal. O traço de Neuroticismo contém sintomas de ansiedade, mas é um construto mais amplo que abrange outras características, o que poderia justificar a correlação positiva. No entanto, Fernandes e cols. (2005) aventaram a hipótese de uma relação negativa entre ambos os construtos.

O autoconceito social também apresentou, exceto para o $2^{\circ}$ ano, correlações negativas moderadas ou próximas de serem magnitudes altas com a ansiedade. Com esse achado, pode-se interpretar que as crianças que se sentem bem preparadas intelectualmente, que gostam de ser melhores do que seus pares, que buscam ajudar os outros e procuram colaboração quando necessário tendem a ser menos ansiosas no contexto escolar. É interessante ressaltar que o inventário de ansiedade contém diversos itens relacionados com as situações sociais na escola, por ser considerada uma dimensão importante nesse contexto. As crianças devem ser capazes de aprender a se manifestar e comportar-se socialmente para serem aceitas por seus pares e professores. Assim, as crianças que apresentam uma melhor socialização e consequentemente um melhor autoconceito social, lidam melhor com as situações sociais na escola e apresentam menores níveis de ansiedade. No mais, a criança na escola pode vivenciar situações ansiógenas que não consiga resolver (Oliveira \& Sisto, 2002), mas a criança com autoconceito social positivo tende a buscar ajuda quando precisa e também se sente capaz intelectualmente, o que contribui para a resolução de problemas e evita a sensação de falta de controle e previsão de eventos potencialmente aversivos, situações típicas da ansiedade (Barlow, 2002). Novamente, esses dados se mostram coerentes com o estudo de Matos e Lobo (2009) e Bandalos e cols. (1995), mas não com o de Fernandes e cols. (2005), que também esperavam relações negativas entre todas as dimensões de Autoconceito com o traço Neuroticismo, mas para os meninos foi positivo e com magnitude baixa.

Apesar de todas as correlações reveladas, não foram identificadas correlações significativas entre as dimensões escolar e familiar do autoconceito com a ansiedade escolar, exceto uma correlação positiva e baixa com a dimensão escolar no $3^{\circ}$ ano. Esse dado para o $3^{\circ}$ ano sugere que quanto mais o aluno se percebe intelectualmente capaz, divertido, bondoso, líder e aceito por seus pares na escola, maior a ansiedade escolar. Tal resultado contradiz as pesquisas citadas e não é o esperado. No entanto, poderia indicar que justamente por se perceber dessa forma dentro do contexto escolar e sendo reforçado pelos professores, pais e colegas por emitir esses comportamentos, o aluno fique preocupado em sempre manter esse padrão de conduta, o que poderia gerar ansiedade. Porém, é um resultado que deve ser mais investigado, principalmente, por ter sido a única correlação baixa que emergiu entre a associação de autoconceito e ansiedade escolar.

As correlações não significativas entre autoconceito escolar e familiar com ansiedade escolar, não eram esperadas e especificamente, a dimensão escolar, não corrobora com o estudo de Matos e Lobo (2009), que revelou uma relação da ansiedade com o autoconceito escolar. Ressalta-se que Matos e Lobo (2009) não investigaram o autoconceito familiar. O dado relacionado com a dimensão familiar não condiz com o trabalho de Fernandes e cols. (2005), que indicou relação negativa entre autoconceito familiar e traço de neuroticismo. Outro resultado que precisa de melhor compreensão, se refere à pouca relação entre autoconceito, em todas as dimensões, e ansiedade escolar para os alunos do $2^{\circ}$ ano. Uma explicação pode advir da questão desenvolvimental do autoconceito, pois conforme pontuado por Carneiro e cols. (2003) a construção do autoconceito é lenta e ocorre pelas experiências que o sujeito vivencia com outros indivíduos. Talvez a sua formação no $2^{\circ}$ ano ainda seja muito precoce.

As análises de regressão efetuadas fortalecem os dados descritos das correlações entre autoconceito e ansiedade escolar encontradas no presente estudo, e mostra que o autoconceito social é a dimensão mais preditiva da ansiedade escolar. Essa dimensão descreve crianças que se 
sentem capazes intelectualmente e solicitam ajuda quando necessário, o que contribui para que resolvam os problemas de forma mais tranquila e rápida, diminuindo a ansiedade que poderia aumentar caso a criança ficasse preocupada, durante um longo período, com situações que não esteja conseguindo resolver.

Concluindo, constatou-se que a relação entre autoconceito e ansiedade escolar tende a ser negativa; quanto maior for o autoconceito positivo, menor a ansiedade. Os achados sugerem a necessidade de programas de intervenção que também trabalhem com o autoconceito das crianças, podendo contribuir para diminuição da ansiedade e consequentemente melhorar o desempenho acadêmico, já que são variáveis associadas ao sucesso escolar. Esse tipo de conhecimento também se faz importante para o professor em sala de aula, que pode intervir com os alunos de forma a facilitar a elaboração de autoconceitos positivos.

Apesar de o estudo ter elucidado melhor a relação entre autoconceito e ansiedade escolar, ainda é imperativo o desenvolvimento de mais pesquisas analisando esses construtos, em especial com crianças mais novas o que possibilitará maior entendimento sobre a pouca associação dessas variáveis em alunos do $2^{\circ}$ ano. Também devem ser feitas pesquisas com maior quantidade de sujeitos e que possam ajudar na investigação da ausência de associação entre as dimensões escolar e familiar com a ansiedade escolar.

Não obstante, ainda se faz necessário elucidar que os construtos investigados, autoconceito e ansiedade, tiveram como coleta da amostra desses comportamentos, dois instrumentos psicológicos bastante úteis, mas que apresentam suas limitações. Como qualquer instrumento psicológico, os utilizados na pesquisa são ferramentas importantes para a investigação dos traços latentes do ser humano, mas para uma melhor investigação de queixas de ansiedade ou autoconceito, é imprescindível que se proceda com uma avaliação psicológica na qual devem ser utilizadas diversas técnicas e instrumentos psicológicos. Diante disso, também é interessante o desenvolvimento de pesquisas sobre a relação autoconceito e ansiedade escolar que utilizem outros instrumentos que mensurem esses mesmos construtos. Assim, haverá mais informações sobre a relação autoconceito e ansiedade escolar advindas de outros instrumentos, fortalecendo os achados sobre a relação entre esses construtos.

\section{Referências}

Asbahr, F. (2004). Transtornos ansiosos na infância e adolescência: aspectos clínicos e neurobiológicos. Jornal de Pediatria, 80 (2, supl), 28-34.

Bandalos, D. L., Yates, K., \& Thorndike-Christ, T. (1995). Effects of math self-concept, perceived self-efficacy, and attributions for failure and success on test anxiety. Journal of Educational Psychology, 87 (4), 611-623.

Barlow, D. H. (2002). Unraveling the mysteries of anxiety and its disorders from the perspective of emotion theory. American Psychologist, 55, 1247-1263.

Berger, C., Alcalay, L., Torreti, A., \& Milicic, N. (2011). Socio-emotional Well-Being and Academic Achievement: Evidence from a Multilevel Approach. Psicologia: Reflexão e Crítica, 24 (2), 344-351.

Carneiro, G. R. S., Martinelli, S. C., \& Sisto, F. F. (2003). Autoconceito e dificuldades de aprendizagem na escrita. Psicologia: Reflexão e Crítica, 16(3), 427-434.

Cia, F., Barham, E. J., \& Fontaine, A. M. G. V. (2012). Desempenho acadêmico e autoconceito de escolares: contribuições do envolvimento paterno. Estudos de Psicologia, 29 (4), 461-470.

Costa, E. R. \& Boruchovitch, E. (2004). Compreendendo relações entre estratégias de aprendizagem e a ansiedade de alunos do ensino fundamental de Campinas. Psicologia: Reflexão e Crítica, 17(1), 15-24.

Craske, M. G., Rauch, S. L., Ursano, R., Prenoveau, J., Pine, D. S., \& Zinbarg, R. E. (2009). What is an anxiety disorder? Depression and Anxiety, 26, 1066-1085.

Dalgalarrondo, P. (2000). Psicopatologia e semiologia dos transtornos mentais. Porto Alegre: ArtMed.

Fernandes, D. C. \& Silveira, A. M. (2012). Evaluación de la motivación académica y la ansiedade escolar y posibles relaciones entre ellas. Psico-Usf, 17 (3), 447-455.

Fernandes, D. C., Bartholomeu, D., Rueda, F. J. M., Suehiro, A. C B., \& Sisto, F. F. (2005). Auto concepto y rasgos de personalidade: um estudio correlacional. Psicologia Escolar e Educacional, 9 (1), 15-25.

Fonseca, M. F. B. C., Cardoso, T. S. G., Muszkat, M., \& Bueno, O. F. A. (2011). Revista Psicopedagógica, 28 (87), 226-236.

Furlam, L. A., Rosas, J. S., Heredia, D., Piemontesi, S., \& Illbele, A. (2009). Estrategias de aprendizaje y ansiedad ante los exámenes en estudiantes universitários. Pensamiento Psicológico, 5 (12), $117-124$.

Matos, A. P. \& Lobo, J. C. (2009). A paralisia cerebral na adolescência: resultados de uma investigação. Psicologia USP, 20 (2), 229-249.

Mychailyszyn, M. P., Mendez, J. L., \& Kendall, P. C. (2010). School Functioning in Youth With and Without Anxiety Disorders: Comparisons by Diagnosis and Comorbidity. School Psychology Review, 39, 106-121.

Oliveira, S. M. S. S. (2012). O Modelo de Rasch para avaliar o Inventário de Ansiedade na Escola. Tese de Doutorado, Programa de Pós-Graduação Stricto Sensu em Psicologia, Universidade São Francisco, Itatiba. 
Oliveira, M. B. \& Soares, A. B. (2011). Auto-eficácia, raciocínio verbal e desempenho escolar em estudantes. Psicologia: Teoria e Pesquisa, 27 (1), 33-39.

Oliveira, S. M. S. S. \& Sisto, F. F. (2002). Estudo para uma escala de ansiedade escolar para crianças. Psicologia Escolar e Educacional, 6 (1), 57-66.

Pereira, A. I. F., Barros, L., \& Mendonça, D. (2012). Cognitive errs and anxiety in school aged children. Psicologia: Reflexão e Crítica, 25 (4), 817-823.

Schiavoni, A. \& Martinelli, S. C. (2012). O autoconceito de estudantes aceitos e rejeitados no contexto escolar. Psicologia Argumento, 30 (69), 297-305.
Seligman, M., Walker, E., \& Rosenhan, D. (2001). Abnormal psychology, (4th Ed.). New York: W.W. Norton \& Company, Inc.

Sisto, F. F. \& Martinelli, S. C. (2004). Manual da Escala de Autoconceito Infanto-Juvenil (EAC-IJ). São Paulo: Editora Psicopedagógica Vetor.

Tinajero, C., Lemos, S. M., Araújo, M., Ferraces, M. J., \& Páramo, M. F. (2012). Cognitive style and learning strategies as factors which affect academic achievement of brazilian university students. Psicologia: Reflexão e Crítica, 25 (1), 105-113.

Recebido em: 06/05/2013

Reformulado em: 12/09/2013

Aprovado em: 09/10/2013

\section{Sobre as autoras}

Monalisa Muniz (mo_nascimento@yahoo.com.br)

Programa de Pós-Graduação em Psicologia, Universidade Federal de São Carlos, Doutora em Avaliação Psicológica.

Débora Cecílio Fernandes (debora.cecilio@gmail.com)

Professora do Departamento de Pedagogia da Universidade Estadual do Centro-Oeste, Guarapuava, Paraná. Doutora em Neuropsicologia Clínica pela Universidad de Salamanca, Espanha. 